\title{
Janela de oportunidade mediada: das mudanças no ânimo das demonstrações de rua ao ativismo online ${ }^{1}$
}

\author{
Larissa Galdino de Magalhães Santos ${ }^{2}$
}

Resumo: $\mathrm{O}$ artigo apresenta reflexões sobre as estruturas de oportunidades políticas de mediação acionadas com o Ciclo de Confrontos iniciado em Junho de 2013. Perante o conflito entre o governo e os movimentos sociais sobre a questão da mobilidade urbana na cidade de São Paulo, as manifestações contra o aumento da passagem do transporte público ganham notoriedade diante da forte repressão da Polícia Militar. Uma nova dinâmica ativista e de interação entre diversos atores é propiciada pelas formas de mediação, ativismo online, estratégias, discursos e práticas comunicativas. O argumento é que Junho de 2013 desencadeia uma janela de oportunidade mediada com o apoio das tecnologias de informação e comunicação, tanto para os movimentos sociais quanto para as instituições. A internet passou a ser palco de representação, legitimação e expansão do conflito, a partir do conteúdo virtual numa nova dinâmica de circulação, troca, colaboração e compartilhamento.

Palavras-chave: movimentos sociais; oportunidades políticas; confronto; discurso; ativismo online; mediação.

\section{Mediated window of opportunity: from the changes in the mood of street demonstrations to online activism}

\begin{abstract}
The article presents reflections on the political mediation opportunity structures triggered by the Cycle of Confronts initiated in June 2013. In the face of the conflict between the government and social movements on the issue of urban mobility

\footnotetext{
${ }^{1}$ Recebido em 29/01/18 e aprovado em 26/05/18.

${ }^{2}$ Doutora em Ciência Política pelo Instituto de Filosofia e Ciências Humanas da Universidade Estadual de Campinas. E-mail: larissagms@yahoo.com.br
} 
in the city of São Paulo, demonstrations against increase in the passage of public transport gain notoriety in the face of the strong repression of the Military Police. A new activist and interaction dynamic between different actors is provided by the forms of mediation, online activism, strategies, discourses and communicative practices. The argument is that June 2013 unleashes a window of opportunity mediated with the support of information and communication technologies for both social movements and institutions. The Internet has become the scene of representation, legitimation and expansion of the conflict, from the virtual content in a new dynamic of circulation, exchange, collaboration and sharing.

Keywords: social movements; political opportunities; confrontation; discourse; online activism; mediation.

\title{
Ventana de oportunidad mediada: de los cambios en el ánimo de las demostraciones callejeras al activismo online
}

\begin{abstract}
Resumen: El artículo presenta reflexiones sobre las estructuras de oportunidades políticas de mediación accionadas con el Ciclo de Enfrentamientos iniciado en junio de 2013. Ante el conflicto entre el gobierno y los movimientos sociales sobre la cuestión de la movilidad urbana en la ciudad de São Paulo, las manifestaciones contra el cambio climático, el aumento del paso del transporte público gana notoriedad ante la fuerte represión de la Policía Militar. Una nueva dinámica activista y de interacción entre diversos actores es propiciada por las formas de mediación, activismo en línea, estrategias, discursos y prácticas comunicativas. El argumento es que Junio de 2013 desencadena una ventana de oportunidad mediada con el apoyo de las tecnologías de información y comunicación, tanto para los movimientos sociales y para las instituciones. La Internet pasó a ser escenario de representación, legitimación y expansión del conflicto, a partir del contenido virtual en una nueva dinámica de circulación, intercambio, colaboración y compartir.
\end{abstract}

Palabras clave: movimientos sociales; oportunidades políticas; comparación; el habla; activismo en línea; mediación.

\section{Introdução}

O ciclo de protestos iniciado em Junho de 2013 ainda está inconcluso, saldos e reformas ainda são avaliados (TATAGIBA, 2014). Impulsionado pelo aumento das tarifas no transporte público, ganhou adeptos e notoriedade a partir dos atos de violência e repressão da Política Militar de São Paulo, gerando 
novas dinâmicas do conflito, oportunidades políticas, limites e constrangimentos à ação coletiva.

A mobilidade urbana na cidade de São Paulo é um caso ilustre sobre atuação das organizações, abertura de espaços de participação, ativismo online e, especialmente o ciclo de protestos de 2013. Vários processos judiciais avolumavam-se, reclamando a existência de leis e espaços para tratar das questões relacionadas ao transporte municipal (BARBOSA, KERBAUY, 2016, 2017).

Somados às reivindicações de leis e espaços para tratar das questões relacionadas ao transporte municipal e pela conjuntura de protestos no nível global como o Indignados na Espanha, Occupy, os novos movimentos coletivos pela luta à cidade e os interesses econômicos (GOHN, 2010) refletem o esforço da análise das mudanças advindas com a internet 2.0 e redes sociais.

Em São Paulo, os protestos de Junho de 2013 reforçou a pauta pela participação política e transparência, também impulsionados pela Política Nacional de Mobilidade Urbana, e a Comissão Parlamentar de Investigação dos Transportes na Câmara Municipal de São Paulo.

As redes sociais foram utilizadas como um fator decisivo de mobilização, para produção e difusão de informações e mídias, repercutindo nas ruas e na ativação de uma nova expertise da ação coletiva (TATAGIBA, 2014).

Diante deste cenário, indica-se que as relações entre os movimentos sociais e o Estado, no contexto do ciclo de protestos, têm impulsionado a mobilização de repertórios complexos, do discurso do conflito, e novas performances da ação coletiva.

Neste artigo analisamos a estrutura de oportunidades políticas para os movimentos sociais a partir do ciclo de confrontos iniciado em 2013, a partir dos repertórios de ação do Movimento Passe Livre e as autoridades da cidade e Estado de São Paulo. Examinamos as oportunidades de mediação, através das redes sociais e do uso de tecnologias de informação e comunicação, da dinâmica contenciosa, novas táticas e estratégias de manifestações combinadas e inovadoras, dos enquadramentos, da visibilidade e mudanças no repertório. 


\section{O ciberativismo, ativismo online e ação coletiva}

Os movimentos sociais emergentes na década de 60 guardam intrínseca relação com o desenvolvimento das tecnologias de informação e comunicação. O metamorfismo cibernético modificou a forma de ser fazer ativismo, através da emergência de novas pautas, novos diálogos direcionados ao Estado pela sociedade civil, através de redes horizontais e não-institucionais.

O ciberativismo é o produto de desenvolvimento das formas de organização social, ação coletiva, manifestações, políticas e culturais ${ }^{3}$. É um fenômeno social inseparável do surgimento das redes telemáticas (ARAUJO, FREITAS, MONTARDO, 2012).

A compreensão das mudanças nos repertórios a partir do uso da internet, indicam que os processos de difusão de repertórios de ação coletiva (TARROW, 2009) no cenário transnacional são modificados e impulsionados pelas novas tecnologias (CARROL, HACKETT, 2006).

O enfoque sobre os movimentos sociais no contexto da internet é essencial para entender a mobilização como um processo que transforma preocupações coletivas em ações, através de mudanças sociais e mediáticas, mobilizações, frames, repertórios, redes e performances (DOWNING, 2008)

Portanto, as manifestações a partir de Junho de 2013 que se espalharam pelo país como um ciclo de confrontos, reforçam a conexão de oportunidades e constrangimentos estruturais, para desafiantes e desafiadores, que possibilitaram inovações estratégicas e táticas como uma janela de oportunidades para os atores.

Ainda que movimentos sociais já utilizassem táticas de ciberativismo, o diferencial foi o impacto e as influências do

\footnotetext{
3 A investigação sobre ciberativismo apresenta marcos para a dinâmica de lutas, tais como o Zapatismo (1994), Batalha de Seattle (1999), queda do presidente das Filipinas (2001) e as revoltas que emergiram no mundo desde as manifestações na Tunísia (2010) ou Primavera Árabe, Occupy, os Anonymous.
} 
contexto e das relações entre os atores, ou seja, as oportunidades políticas criadas para todos os pares em conflito.

\begin{abstract}
Os movimentos sociais se desenvolvem dentro de limites colocados por estruturas prevalecentes de oportunidade política: as organizações formais de governo e de políticas públicas; a facilitação e a repressão das reivindicações dos grupos desafiantes por parte das autoridades e a presença de aliados potenciais, rivais ou inimigos afetam, de forma significativa, qualquer padrão de confronto do sistema político (MCADAM, TARROW, TILLY, 2009, p.26).
\end{abstract}

Logo a popularização e expansão da web proporcionou a organização de ativistas pela rede e ações de hacktivismo, de modo que o caráter interativo da web 2.0, facilitou as estratégias em outras mídias e dispositivos (ARAUJO, FREITAS, MONTARDO, 2012). As novas formas de ação coletiva refletem a própria forma de desenvolvimento disruptivo da internet, e no modo de utilização dos novos dispositivos utilizados no e para o confronto.

Por outro lado, o ciberativismo foi influenciado por um discurso metamorfoseado para distribuição do poder, acesso às informações, emancipação social, engajamento e mobilização (SILVEIRA, 2010; ANTOUN, MALLINI, 2010; LIEVROUW, 2011).

Portanto, os novos movimentos sociais, em toda sua diversidade, reagem contra a globalização e seus agentes políticos, atuando com base em processo contínuo de informacionalização por meio da mudança nos códigos culturais no cerne das novas instituições sociais. Nesse sentido, não obstante surgirem das profundezas de formas sociais historicamente esgotadas, afetam de modo decisivo a sociedade atualmente em formação, seguindo um padrão bastante complexo (CASTELLS, 1999, p.135). 
$|82|$

Janela de oportunidade mediada:...

As redes sociais enquanto "esfera pública interconectada", tornou-se palco para disseminar e debater questões relevantes ao interesse público e que, portanto, requerem o reconhecimento coletivo para uma ação coordenada no mundo online e offline (BENKLER, 2006).

Como apontam Antoun e Malini (2010), Malini (2012), a rede é um "entre lugar", um campo de disputas sociais, em que são negociadas a atuação, a mobilização e as formas de engajamento como mecanismos operacionalizáveis em rede. Trata-se de

(...) uma estratégia para formar coalizões temporais de pessoas que utilizando ferramentas dessa rede, geram a massa crítica suficiente de informação e debate, para que este debate transcenda à blogosfera e saia à rua, ou modifique, de forma perceptível, o comportamento de um número amplo de pessoas (UGARTE, 2008, p. 111).

O ativismo e a mídia reuniram novas rotas híbridas de ação, como a contracultura, a computação alternativa e hackeamento, a subversão da lógica da mass media, e a mobilização mediada que combina as interações online e offline para produção de informações e saberes através do conhecimento compartilhado (LIEVROUW, 2011).

Assim, o ativismo online é um promotor para transformação do poder (CARROLL; HACKETT, 2006), como "instrumento de participação, mobilização e criação de identidade" (BRINGEL, MUÑOZ, 2010, p. 30). O ativismo online é uma característica essencial do ciclo de protestos.

Ao longo da dinâmica do ciclo de protesto, tanto Estado como os movimentos sociais, lançaram mão dos dispositivos online produzindo novos discursos, performances e viabilizando o surgimento de outros atores.

$\mathrm{Na}$ ausência dos atores políticos tradicionais, com seus recursos e expertise na ativação da ação coletiva, o papel de mobilização e recrutamento nos protestos contra o aumento da tarifa foram desempenhados 
principalmente pelas redes sociais. O ciclo de protestos de Junho não foi construído nas redes sociais. Mas, sem dúvida a mobilização nas redes foi um fator decisivo para a conformação de suas características. As redes sociais foram um espaço essencial para a produção e difusão de informação alternativa às veiculadas pela mídia tradicional, principalmente a partir dos vídeos feitos pelo celular. Os debates realizados nas redes repercutiam o clima da rua; a mobilização gerada na rede construía o desejo de ir para a rua (TATAGIBA, 2014, p.15).

Se a organização da ação coletiva contemporânea está relacionada à comunicação alternativa e as mídias digitais (BENNETT, SEGERBERG, 2012), avançamos para novas estruturas e oportunidades políticas, lógicas e dinâmicas das manifestações e dos repertórios de ação coletiva.

\section{Estruturas e oportunidades políticas: potenciais e limites}

O contexto político-institucional exerce papel decisivo na emergência da ação coletiva. Existe uma estrutura de incentivos e/ou constrangimentos a partir da qual os atores decidem ou não se engajar no confronto. Estruturas de oportunidades políticas favoráveis viabilizam o surgimento do movimento social, somadas a estrutura de mobilização (MAcADAM, TARROW, TILLY, 2010). Assim,

A política do confronto é produzida quando as oportunidades políticas se ampliam, quando demonstram potencial para alianças e quando revelam a vulnerabilidade dos oponentes. O confronto se cristaliza em movimento social quando ele toca em redes sociais e estruturas conectivas embutidas e produz quadros interpretativos de ação coletiva e identidades de apoio capazes de sustentar o confronto com oponentes poderosos (TARROW, 2009, p.43). 
$|84|$

Janela de oportunidade mediada:...

As condições operadas nas estruturas de oportunidades e restrições políticas, são dimensões consistentes de encorajamento e desencorajamento à ação coletiva, que estabelecem as condições ou limites nos quais o confronto tende ou não a se manifestar. Mudanças na estrutura de oportunidades e restrições políticas produzem alterações no nível da agência coletiva.

São as estruturas de oportunidades que delimitam a possibilidade de escolha dos agentes entre os melhores cursos de ação para política de confronto. Quando há mudanças nas estruturas, seja nas dimensões formais e informais, se abrem ou se criam canais para expressão de reivindicações para aqueles grupos sociais que estão fora da esfera política (TARROW, 1998, p.20).

Entretanto, as oportunidades não são aproveitadas somente pelos mobilizados, mas também por seus oponentes, ao especularem e informarem suas ações, resultando na criação do espaço político para o movimento e para o contra movimento, produzindo incentivos e provocando a reação dos oponentes (TARROW, 2009).

Especificamente no episódio desencadeador do ciclo de protestos em Junho de 2013, o Movimento Passe Livre e Polícia Militar (considerando a relação do governo municipal e estadual), foram modificando as estratégias e ação, logo a dinâmica do conflito. Foram incorporadas outras estratégias de ação ao longo ciclo, aproveitando as oportunidades políticas, como a mediação através do uso das redes sociais (que é foco analítico aqui proposto), coalizões e formas de protesto e repressão.

A interação e confronto disseminados através do ciclo de protestos produziu uma determinada vantagem aos desafiantes no uso das redes sociais e tecnologias, e exigiu que o Estado organizasse estratégias de reação (TARROW, 2009, p.182).

A vantagem temporária da novidade, seja pela organização nas redes sociais; seja pela veiculação, através do jornalismo participativo das estratégias de violência e repressão da polícia; e da visibilidade, denotam novos quadros interpretativos, conflitos pelo discurso, em que o Estado teve que combinar novas estratégias para lidar com as manifestações sobre o transporte público. 
O ciberativismo em redes sociais e sequência de eventos combinados no início do ciclo de protestos são parte da estrutura de oportunidades que facilitaram um novo curso da ação coletiva, mas também um novo repertório de confronto.

Dentre as atividades e ferramentas utilizadas no ciclo destacam-se: dinamização de ações virtuais advindas do legado da cultura hacker; visibilidade e circulação de informação descentralizada; deliberação para um novo consenso social ou ciberturba (UGARTE, 2008); ferramentas que potencializam a interação instantânea; desenvolvimento de dispositivos móveis e ampliação das redes de conexão sem fio; articulação transnacional de redes de ativistas mobilizáveis; dispersão da noção de tempo e espaços e agilidades nas interações coordenadas; mídia alternativa e a produção de informação cooperativa, de forma livre e pública (ANTOUN, MALLINI, 2010); redes sociais virtuais para organização e articulação de coletivos personalizados; ubiquidade (LEMOS, JOSGRILBERG, 2009).

A estrutura de oportunidades políticas incorporou táticas virtuais e lógicas mediadas de ação coletiva para o confronto. Essa estratégia opera como estruturas de oportunidades políticas de mediação, atuando internamente por meio de formas de ativismo online e externamente como mídia alternativa.

$\mathrm{O}$ ciclo de confrontos retroalimenta as oportunidades políticas e reelaboram novos cursos de ação.

\begin{abstract}
(...) são produtos de uma difusão mais ampla de oportunidades políticas que transformam o potencial para a mobilização em ação. Nesses cadinhos de conflito e inovação, os desafiantes e seus opositores não apenas tiram vantagem de oportunidades disponíveis, eles as criam para outros ao produzir novas formas de ação, elaborando novos "quadros interpretativos principais" e fazendo coalizões que forçam o Estado a reagir à desordem em volta dela (TARROW, 2009, p.251).
\end{abstract}


$|86|$

Janela de oportunidade mediada:...

A mudança na estrutura de oportunidades políticas gerou espaço e inovações para mobilização coletiva, e espaços para atuação de todos atores. Portanto, o ciberativismo facilita também o desenvolvimento de uma janela de oportunidade política.

Argumentamos que a internet como uma "habilidade temporária" que toca desprevenidamente seus oponentes, interfere nas estruturas de mobilização, e passa a exigir do oponente um desempenho diferente e correspondente à inovação.

Durante os primeiros anos do ciclo de confrontos (2013-2015) o Movimento Passe Livre utilizou a internet como inovação para mobilização, criando uma forma de ação diferenciada. Contudo, se em 2013 as autoridades foram surpreendidas pelos movimentos sociais, em 2015, durante outro pico de manifestações, as autoridades, especialmente a Política Militar de São Paulo, passaram a agir também nas redes e através de tecnologias.

As autoridades produziram novas formas de ação, estabeleceram novas coalizões com outros movimentos envolvidos com a causa da mobilidade urbana. E através da janela de oportunidades acessada pelo Movimento Passe Livre, as instituições também passaram a utilizar as redes sociais para elaboração de um quadro interpretativo, baseado no conflito de discursos, como uma oportunidade política de mediação

Portanto, o ciberativismo acessado no ciclo iniciado em 2013 viabilizou uma janela de oportunidade política e a oportunidade política de mediação. Ou seja, novas formas de conflitos baseadas nas ações através das redes sociais.

\section{É preciso estar em movimento: sobre oportunidades convencionais e janela virtual}

As oportunidades políticas fazem referência a sinais contínuos, embora não permanentes, que são percebidos pelos atores. Na medida em que o ciclo de oportunidades se estreita, movimentos e autoridades se modificam. 
Os confrontos políticos ocorridos a partir das manifestações de Junho de 2013, e as táticas de repressão às manifestações adotadas pelo Estado, tornaram-se o estopim para a introdução de outros grupos e pautas nas manifestações. Também, utilizando das capacidades, já citadas, ofertadas pelas tecnologias às mobilizações, ampliou-se a visibilidade do "par de atores" em conflito, oferecendo informações alternativas à mass media e expondo a dinâmica do confronto.

A transformação na estrutura de oportunidades perante as ameaças políticas e a propensão do uso da violência política pelo Estado favoreceram a onda de mobilizações inovadoras, uma vez que

(...) as pessoas se engajam em confrontos políticos quando mudam os padrões de oportunidades e restrições políticas e, então, empregando estrategicamente um repertório de ação coletiva (inovador), criam novas oportunidades que são usadas por outros, em ciclos mais amplos de confronto (TARROW, 2009, p.38).

A janela de oportunidades possibilitou o surgimento da ação coletiva com repertório renovado. Isto porque as novas tecnologias de informação e comunicação, em especial a internet é incorporada como mecanismo do repertório de ação, dando substância a janela de oportunidade política de mediação.

O Movimento Passe Livre e outros setores mobilizados já incorporavam o uso das redes sociais como técnica para o repertório de ação no início do ciclo, o que lhe promove o caráter de inovação. Ademais, em 2013, as autoridades responderam com repressão efetiva, exacerbando a polarização reacionária, para depois ceder às reinvindicações dos manifestantes (TARROW, 2009, p.190-191).

Contudo em 2015, diante de manifestações baseadas em repertórios de ação já reconhecidos, as autoridades utilizam a janela de oportunidade política para a desmobilização através da oportunidade política de mediação. 
$|88|$

Janela de oportunidade mediada:...

A conjuntura político e social desde 2013 incitou novas formas de protestos, principalmente pela midialização da violência e repreensão exacerbada do Estado mostrada pelos movimentos nas redes sociais, o que culminou na adesão de outros grupos aos movimentos. Num sentindo amplo, o uso e incorporação das novas tecnologias como táticas e lógicas de ativismos, são entendidos como janelas de oportunidades políticas de mediação.

Enfatizamos que o recente ciclo de protestos e novos repertórios de ação dos movimentos no país não começaram na internet, mas o ciberativismo favoreceu a elaboração de novas táticas e lógicas de ativismos. Concomitantemente, abriu-se uma janela de oportunidades políticas, especialmente de mediação, uma vez que o universo comunicacional e tecnológico foi palco para visibilidade, conflito e discurso.

Entretanto, não foram somente os movimentos sociais que operaram através de oportunidades políticas de mediação, as autoridades reelaboraram seu curso de ação em resposta ao novo repertório dos movimentos sociais a partir de 2013.

A oportunidade política de mediação está relacionada à dimensão dos incentivos e constrangimentos de mediação, ativismos e discursos em rede, das práticas e estratégias comunicativas (CAMMAERTS, 2013). Argumentamos que Junho de 2013, e o conflito sobre as questões de mobilidade urbana em São Paulo propicia, principalmente, estruturas que comportam a oportunidade política de mediação online.

Junho de 2013 e a oportunidade política de mediação: mídia, discurso e rede

A mediação nos interessa por que "é um conceito eficiente para abranger uma grande variedade de maneiras nas quais a mídia e os meios de comunicação são relevantes para os protestos e movimentos" (CAMMAERTS, 2013, p.13).

A mediação permite abordar a mídia, e os conteúdos produzidos - informações, narrativas e discursos - em conjunto com as novas tecnologias, "como estratégias de comunicação e 
práticas midiáticas de cidadãos e ativistas" (CAMMAERTS, 2013, p.14), logo tem relação com a estrutura de oportunidade política de mediação.

De acordo com Gohn (2010) as formas de organização e das ações são reconfiguradas pela apropriação de ferramentas de comunicação diversificadas, já que favorece a articulação e as estratégias de visibilidade dos movimentos sociais. As oportunidades potenciais, diante das limitações estruturais retratam a proposta de novas formas de organização da sociedade, enquanto inovações para mudança social (GOHN, 2004).

A oportunidade de mediação política é composta por outras três estruturas: estrutura de oportunidade mídia, estrutura de oportunidade discursiva e a oportunidade em rede. Numa aproximação com os movimentos sociais, as oportunidades de mídia referem-se à ampliação do coletivo alternativo, das ferramentas e da lógica de rede. A estrutura de discursos é corroborada pela circulação e pelo espelhamento do conteúdo elaborado para o meio e a partir do meio virtual. Da oportunidade de rede, das formas de circulação, fluxo, troca, compartilhamento, colaboração e descentralização (CAMMAERTS, 2013).

A estrutura de oportunidade de mídia serve ao desempenho e representação, com a finalidade da mobilização, da legitimação, da validação das demandas, expansão do conflito para além do compartilhamento de opiniões (GAMSON, WOLFSFELD, 1993). Estrutura de oportunidade de discurso está relacionado à luta simbólica, interna e externa do conflito, na medida em que as ações são produtoras de novas ideias e agentes de contestação de formas e ideais retrógadas, logo contribuem para formação de identidades coletivas (MELUCCI, 1996). Já a estrutura de oportunidade em rede, como instrumental e constituinte, contribui para as estratégias de planejamento (BENFORD, SNOW, 2000), bem como nas formas de organização e mobilização autônomas.

Inevitavelmente, a relação entre essas três estruturas de oportunidades inter-relacionadas é circular - cada uma delas tem impacto nas outras de diferentes formas (CAMMAERTS, 2013, p.17). 
$|90|$

Janela de oportunidade mediada:...

Seguidamente, apresentamos algumas táticas, recursos, estratégias e ações que foram introduzidas com a estrutura de oportunidade políticas de mediação de Junho de 2013. Mídia, discursos e rede são componentes estruturais importantes nas novas performances e ações coletivas.

\section{Estrutura de oportunidade de mídia e o ciclo de protestos ${ }^{4}$}

A estrutura de oportunidade de mídia refere-se à representação sobre as manifestações, cuja lógica tradicional tende a receber menos atenção da mídia, a não ser que exista algo de espetacular nisso. A atenção da mídia pode ser conquistada pela lógica dos números através de manifestações de massa, pela lógica do dano, através da destruição de propriedade (tática black bloc), pela lógica do testemunho, e pela exibição pública (DELLA PORTA, DIANI, 2006).

Sobre os números, quando das manifestações organizadas pelo Movimento Passe Livre, nas primeiras semanas de janeiro de 2015, os organizadores relatam aglomerações de até 30 mil pessoas, enquanto, segundo a Polícia Militar não passam de $5 \mathrm{mil}$ mobilizados.

Com o benefício das tecnologias, usando imagens, músicas, transmissões simultâneas, produções artísticas, os movimentos sociais desafiam discursos hegemônicos. A intenção facilitar a reflexão e reinterpretação sobre as demandas públicas e relevância em defende-las. É um processo de legitimação interna, de uma

\footnotetext{
${ }^{4}$ Foram feitas pesquisas em diversas fontes documentais, sites, revistas e jornais sobre a atuação dos movimentos sociais no biênio (2013-2015) tomando como base os movimentos relacionados às Manifestações de Junho de 2013, Copa do Mundo de 2014 da Fifa, Eleições Presidenciais de 2014. Foi realizada a análise documental de 27 documentos entre 01/01/2015 e 31/01/2015. O intuito foi compreender perceber de que forma a estrutura de oportunidades de mediação permite a apreensão sobre diferentes atores de mídia, diferentes formas de organização, estratégias e lógicas de comunicação, pelos atores na dinâmica do confronto.
} 
mídia coletiva e alternativa, com blogueiros de rua, e outras formas que diversificam das formas da mídia tradicional.

O Mídia NINJA (Narrativas Independentes, Jornalismo e Ação), por exemplo, coletivo que utiliza tecnologias para apoiar ações coletivas, ganhou notoriedade por transmitir pela internet os protestos de Junho de 2013 utilizando celulares, laptops e outros dispositivos. Destaca-se como um coletivo alternativo que opera em várias lógicas e estruturas de oportunidade de mediação. Nomeiam-se enquanto mídia radical dedicada à mídia livrismo, estabelecido na luta anticapitalista.

\title{
Estrutura de oportunidade de discurso
}

Como mídia alternativa, os movimentos investem em recursos para ser a mídia o principal veículo capaz de formar ou influenciar a opinião pública e do público. Assim investem na produção de contra narrativas, novos enquadramentos, artefatos de protestos, constroem identidades coletivas, promovem novas identidades, ridicularizam as elites, através das lutas simbólicas.

\begin{abstract}
A natureza material e permanente desses artefatos de protesto permite que símbolos e discursos sejam inseridos neles para serem culturalmente transmitidos no longo prazo, alimentando o embate e contribuindo para a construção da memória coletiva de protesto. Com isso, eles efetivamente se tornam "comunidades epistêmicas" (Lipschutz, 2005), transferindo o conhecimento e potencialmente influenciando outros movimentos através do que é chamado "transbordamento de movimento" (Meyer e Whittir, 1994) (CAMMAERTS, 2013, p. 24).
\end{abstract}

Após as manifestações de Junho de 2013, a tática black bloc de desobediência civil através da violência patrimonial foi identificada como o próprio Movimento Passe Livre, a estrutura de oportunidade de discurso age interna e externamente, para lograr a identidade de um movimento com lógicas para o diálogo 
e outra tática confrontacional e muitas vezes relacionado à criminalização.

Sobre as tecnologias, surgiram as multidões inteligentes, formadas por agrupamentos de pessoas capazes de agir de forma coordenada mesmo sem se conhecerem previamente, mas mobilizadas pela sinergia da interconexão pela computação móvel, redes sem fio e telefonia. É a identificação pela solidariedade.

Para Lasén e Albéniz (2008) os recentes movimentos possuem caráter lúdico e performático, com ênfase na sociabilidade, com base numa comunicação computacional, mas também emocional, tecnologicamente mediadas, e compartilhadas, expondo a narração das ações na rede.

\begin{abstract}
Muito se tem dito sobre a presença de milhares de jovens nas ruas deste Brasil. Trata-se de uma nova geração, com outras referências, códigos, sociabilidades, identidades e desejos que a maioria ou a velha guarda não consegue captar - talvez algo desde o início e em essência já desmanchado no ar. Na rua, lutas, ideologias, discursos, ações, sentidos, performances, teatralizações e desobediência civil em direções diversas, opostas e semelhantes, que acabam por se aglutinar em torno de uma única noção identificada: protesto (BALLESTRIN, 2013). ${ }^{5}$
\end{abstract}

\title{
Estrutura de oportunidades em rede
}

As oportunidades em rede vão de encontro a ideia de estrutura descentralizada e ponto a ponto disseminada na rede, internet. As tecnologias facilitam as ações coletivas através do recrutamento, mobilização, coordenação da ação militante, e as características de associação e interação da rede de mundial de computadores.

\footnotetext{
${ }^{5}$ Os protestos no Brasil e o desafio às Ciências Sociais. Luciana Ballestrin Coordenadora do Curso de Relações Internacionais da UFPel. Revista Carta Maior.
} 
As práticas de comunicação dos ativistas não são, entretanto, meramente limitadas pelo uso da mídia e comunicação como armas discursivas, nem tampouco pode o uso das TICs por ativistas ser reduzido a meros facilitadores de protesto no mundo offline. As TICs também tornaram-se instrumentos de ação direta por conta própria, com táticas de hacktivismo ou até mesmo como os movimentos de Software Livre e Código Aberto demonstram (Jordan e Taylor, 2004; Söderberg, 2007). O coletivo de hackers Anonymous é um exemplo muito recente disso (CAMMAERTS, 2013, p.28).

As redes legitimam as ruas, e as ruas por sua vez legitimam a rede. Os movimentos sociais são um poder em movimento, e a relação rede, tecnologias e ações coletivas são cada vez mais híbridas. Ainda que a rua seja o elemento chave, o palco, o discurso, a narrativa, a notícia, a performance, o inesperado é construído com as contribuições da rede, é aí que o ativista online constrói suas ideias e afeta as pessoas. A rede é um espaço de autonomia para os movimentos sociais em rede:
(...) interação do espaço de fluxos na internet e as redes de comunicação sem fio com o espaço dos lugares ocupados (...) e assim (...) o espaço da autonomia é a nova forma espacial dos movimentos sociais em rede (CASTELLS, 2013, p. 160-161).

As comunidades virtuais e mobilizáveis dispersas, que formam uma multidão, começam a se estruturar e a experimentar suas formas singulares de luta e organização na rede. A multidão só existe na luta e existe, significativamente, porque luta.

Dahlberg (2011) indica a interpretação de contrapúblico, como modelo para pensar a democracia e as novas tecnologias, com base em duas suposições: as formações sociais envolvem relações de contestação discursiva e prática; justamente o antagonismo favorece a formação de contradiscursos que contestam o hegemônico e o dominante. 
A mídia digital pode incluir discursos minoritários e excluídos, conectando diferentes vozes e contradiscursos, constrangendo e limitando a esfera pública. São, portanto, cidadãos ativos, não mais através dos canais tradicionais, nem necessariamente dos representantes - oportunidade política de mediação - mas utilizando as tecnologias como expressão alternativa e providenciando visibilidades, ou ainda, agendando novas discussões públicas (PÄIVÄRINTA, SÆBØ, 2006).

Incluem-se novas formas de ativismo online, utilizando sites próprios, redes sociais, e outras mídias alternativas, destacandose ações de desobediência civil eletrônica, e até mesmo o ativismo presencial, facilitado e coordenador através do apoio da comunicação digital (DAHLBERG, 2011, p. 862).

A estrutura de oportunidades em rede amplia as chances para os ativistas comunicarem para além daqueles que se identificam, ampliam, pois, a solidariedade social, distribuindo discursos alternativos contribuindo para construção de identidades coletivas, mas também facilitando as ações, construindo outras redes e conexões, por meio da arquitetura da própria rede.

\section{Considerações finais}

Oportunidades políticas exigem novas formas e estratégias de ação coletiva, ou seja, repertórios de ação. Os repertórios emergem a partir da dinâmica conflitiva, como os protestos de Junho de 2013, e não pertencem especificamente a um movimento, cuja eficácia deriva da novidade temporária.

A ideia de oportunidade política mediada enquanto dinâmica de conflito, está baseada na interação, na medida em que os movimentos constituem estas estruturas de oportunidades, para suas causas, para outros, e até mesmo para seus oponentes. Logo o Movimento Passe Livre, com o ciclo de protestos iniciado em 2013, possibilitou a constituição de oportunidades políticas de mediação, principalmente via internet, incorporando táticas e estratégias ao seu repertório de ação, mas estas mesmas estruturas incitaram possibilidades para as autoridades, responderem e incorporarem novas formas de ação diante as manifestações recentes em 2015. 
Na tentativa de enfraquecer o movimento, o governo mudou sua tática e estratégia de ação em 2015. A prefeitura de São Paulo, reuniu-se com outros representantes dos movimentos sociais com o objetivo de enfraquecer as manifestações do Movimento Passe Livre, e fomentando a articulação de passeatas para os movimentos paralelos. Houve a abertura do sistema político formal para a criação de alianças para desestabilizar as coalizões.

Por outro lado, movimentos sociais tradicionais estavam insatisfeitos com o protagonismo do Movimento Passe Livre. O governo explorou o descontentamento, promovendo a formação de um diálogo permanente com outros movimentos estudantis, que passaram a repudiar as ações daquele movimento. Esse conjunto de movimentos e aliados criou uma pauta própria e paralela ao Movimento em 2015.

As táticas de repreensão do Estado desde as manifestações de 2013 para 2015, também mudaram. A Polícia "evitou" agressões à impressa, e procurou promover a visibilidade de seu próprio discurso, como oportunidade política mediada criando páginas personalizadas nas redes sociais. Logo, se em 2013, a polícia foi incitada pela guerra nas mídias, tradicionais e virtuais, em 2015, a corporação evidenciou sua perspectiva sobre os fatos e mobilizações como verdade.

Deste modo, a internet, que contribui para notoriedade e articulação das manifestações contrárias à tarifa do transporte público, exibindo a "batalha" entre a Política Militar de São Paulo e os estudantes, em Junho de 2013, tornou-se objeto de disputa e domínio durante as manifestações de 2015.

Após ter sua imagem relacionada à violência e repressão nos atos de 2013, a Polícia Militar decidiu utilizar a internet para divulgar a sua versão dos fatos e mobilizar a opinião pública.

O conflito discursivo mais presente nas, e sobre as, manifestações de 2015 evidenciam a oportunidade para conquista de visibilidade e espaço para defesa dos movimentos sociais, são, pois, oportunidades políticas de mediação. Mas as táticas e estratégias empregadas no conflito discursivo nas manifestações em 2013, e que foram um diferencial através das redes sociais, 
já não são desconhecidas para as autoridades. Como resposta às manifestações de 2013, considerando o ciclo de protestos em aberto, a Polícia Militar de São Paulo e a prefeitura, utilizaram tipos de oportunidades políticas a seu favor.

Assim, vale lembrar que a intervenção política em âmbitos sociais e institucionais perpassa a visibilidade e o discurso, ou seja, a oportunidade política de mediação.

O discurso público não é um dado, mas é um produto resultante de um complexo jogo de interações no qual intervêm, certamente, os objetivos e os interesses dos grupos de poder e dos aparatos políticos, e para o qual contribuem com um papel não subalterno seja as competências profissionais e as dinâmicas organizativas dos adeptos aos trabalhos, seja as escolhas dos consumidores da comunicação (MELUCCI, 2001, p.144).

\section{Referências}

ANTOUN, Henrique; MALINI, Fabio. Ontologia da Liberdade na Rede: as multi-mídias e os dilemas da narrativa coletiva dos acontecimentos. In: XIX COMPÓS - 19 Encontro Anual da Associação Nacional dos Programas de Pós-Graduação em Comunicação, 2010, Rio de Janeiro. XIX COMPÓS, PUC-RIO 2010, Anais do XIX Encontro Anual da COMPÓS. Rio de Janeiro: COMPÓS e PUC-RIO, 2010. v. 1. p. 1-14.

ARAÚJO, W., F.; FREITAS, E., C.; MONTARDO, S., P. Ciberativismo como cultura de mobilização imanente à internet. In: PUHL, Paula Regina; SARAIVA, Juracy Assmann. (Org.). Processos culturais e suas manifestações. 1 ed. Novo Hamburgo: Feevale, 2012, v. 1, p. 163-190.

BARBOSA, G. H.; KERBAUY, M.T.M. Inclusividade e mobilidade urbana na cidade global: a institucionalização da participação em São Paulo. In: III Encontro Internacional Participação, Democracia e Políticas Públicas, 2017, Vitória. Anais III Encontro PDPP, 2017. v. 3. p. $407-430$. 
- Movimentos sociais e institucionalização da participação: os Protestos de Junho de 2013 e a criação do Conselho Municipal de Transporte e Trânsito de São Paulo. In: $40^{\circ}$ Encontro Anual da Anpocs, 2016.

BENFORD, R.; SNOW, D. Framing Processes and Social Movements: An Overview and Assessment. Annual Review of Sociology, 26: 611-39. 2000.

BENKLER, Y. The wealth of the networks: how social production transforms markets and freedom. Londres: Yale University Press, 2006.

BENNETT, L., W.; BREUNIG, C.; GIVENS, T. Communication and Political Mobilization: Digital Media Use and Protest Organization among Anti-Iraq War Demonstrators in the U.S'. Political Communication, 25(3): 269-89. 2008.

BRINGEL, B.; MUÑOZ, E., Et. Dez anos de Seattle, o movimento antiglobalização e a ação coletiva transnacional. Ciências Sociais Unisinos, 2010, p. 28-36.

CAMMAERTS, B. Lógicas de protesto e a estrutura de oportunidade de mediação. Matrizes, São Paulo, ano 7, n.2, p. 13-36, 2013.

CARROLL, W., K.; HACKETT; R., A. Democratic media activism through the lens of social movement theory. Media, Culture \& Society. 2006, p. 83-104.

CASTELLS, M. Redes de indignação e esperança: Movimentos sociais na era da internet. Rio de Janeiro: Zahar, 2013.

A sociedade em rede. São Paulo: Paz e Terra,1999.

DAHLBERG, L. Re-constructing digital democracy: An outline of four positions. New Media \& Society, V. 13, N. 6, p. 855-872, 2011.

DELLA PORTA, D.; DIANI, M. 2006. Social Movements: an introduction. Oxford: Blackwell.

DOWNING, J. Social Movement Theories and Alternative Media: an Evaluation and Critique. Communication, Culture \& Critique, 2008, p. 40-50. 
GAMSON, W.; WOLFSFELD, G. Movements and Media as Interacting Systems. Annals of the American Academy of Political and Social Science, 526: 114-27. 1993.

GOHN, M., G., M. Movimentos sociais e redes de mobilização civis no Brasil contemporâneo. Petrópolis: Ed.Vozes, 2010.

- Novas teorias dos movimentos sociais: paradigmas clássicos e contemporâneos. São Paulo: Edições Loyola, 2004.

LASÉN, A.; ALBÉNIZ, I., M. Movimientos, "mobidas" y móviles, um análisis de las masas mediatizadas. In: SÁDABA, Igor; GORDO, Ángel (Orgs). Cultura digital y movimientos sociales. Madrid: Catarata, 2008.

LEMOS, A.; JOSGRILBERG, F. Comunicação e Mobilidade. Aspectos Socioculturais das Tecnologias Móveis no Brasil. Salvador, Edufba, 2009.

LÉVY, P. As tecnologias da Inteligência: O futuro do pensamento na era da informática. São Paulo, editora 34, 1993.

MALINI, F. Monitoramento, vazamentos e anonimato nas revoluções democráticas das redes sociais da internet. Revista Fronteiras (Online), v. 14(2), p. 68-76, 2012.

LIEVROUW. L., A. Alternative and activist new media. Polity Press, 2011.

McADAM, D.; TARROW, S.; TILLY, C. Para mapear o confronto político. Lua Nova, $n^{\circ}$ 76, pp. 11-48, 2009.

MELUCCI, A. Challenging Codes: Collective Action in the Information Age. New York: Cambridge University Press, 1996.

SILVEIRA, S. A. Ciberativismo, cultura hacker e o individualismo colaborativo. Revista USP, São Paulo, v. v.1, p. 28-39, 2010.

TARROW, S. O poder em movimento: movimentos sociais e confronto político. Petrópolis: Editora Vozes, 2009.

. Power in Movement. Social movements and contentious politics. Cambridge: Cambridge Univ. Press. 1998. 
TATAGIBA, Luciana. 1984, 1992 e 2013. Sobre ciclos de protestos e democracia no Brasil. Revista Política \& Sociedade. UFSC, 2015.

UGARTE, D. O poder das redes. Manual ilustrado para pessoas, organizações e empresas chamadas a praticar o ciberativismo. Porto Alegre: EDIPUCRS, 2008. 
